\title{
2 Achieving Multiple Sustainable Development Goals through Saline Agriculture
}

Katarzyna Negacz, Bas Bruning, and Pier Vellinga

\section{CONTENTS}

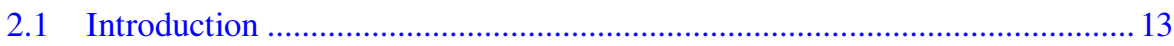

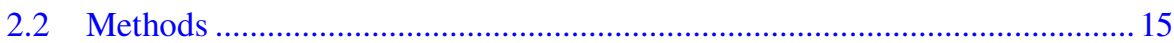

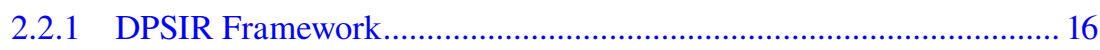

2.2.2 Semi-Structured Interviews ......................................................... 17

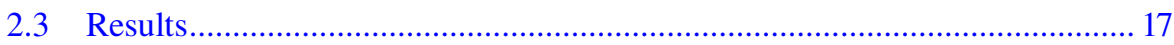

2.3.1 From Drivers to Responses: SDGs in the Saline Agriculture …......... 17

2.3.2 SDGs according to Experts ............................................................... 19

2.3.2.1 SDG 2: Conditions for the Introduction of Salt-Tolerant Crops ............................................................20

2.3.2.2 SDG 8 and SDG 12: Impact on Economic Development and Scalability ............................................... 21

2.3.2.3 SDG 4 and SDG 15: Possible Trade-Offs .............................22

2.3.2.4 SDG 13: Impact of Climate Change ......................................23

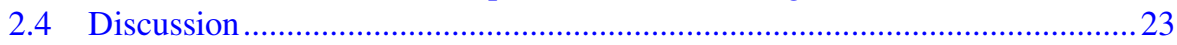

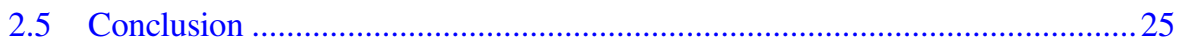

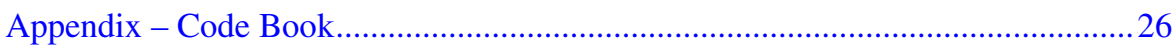

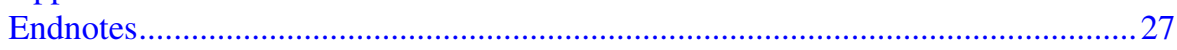

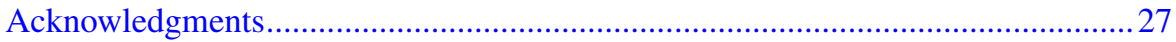

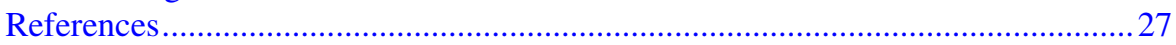

\subsection{INTRODUCTION}

Recent research shows that saline agriculture is gaining popularity as a management technique for saline soils (Dagar et al. 2016, 2019; De Waegemaeker 2019). This form of revitalisation is an integrated approach addressing multiple sectors at the same time. There is a need to better understand the impact of saline agriculture on society, the economy and the environment as well as to uncover potential synergies and trade-offs within saline agriculture. The United Nations Sustainable Development Goals (SDGs) provide a systematic and reliable framework to address nexus topics (Stoorvogel et al. 2017; Hülsmann \& Ardakanian 2018; Liu et al. 2018; 
van Noordwijk et al. 2018). These goals were set by the United Nations in 2015 as a way to achieve a more sustainable future. Table 2.1 presents the list of the goals with their main focus. We argue saline agriculture can best be viewed as a multi-sectorial topic, as it acts across multiple sectors and touches upon multiple SDGs.

Soil salinization is one of the reasons for soil degradation and has an impact on land use, water supply, soil fertility, and plant (and animal) community composition. It is defined as the accumulation of water-soluble salts in the soil to a level that impacts agricultural production, environmental health, and economic welfare (FAO 2011). Salinization is a worldwide problem occurring on more than 400 million ha (more than twice the total area of European farmland) and the salt-affected land area is likely to increase rapidly as a result of climate change and sea-level rise (JoeWong et al. 2019). It occurs in more than 75 countries on $20 \%$ of the global irrigated land (Ghassemi et al. 1995). It creates both land and water issues, having a major impact on land productivity and crop production (Datta \& Jong 2002). Salinity has an adverse effect on crops because a low osmotic pressure hampers the absorption of water and because soluble salts can accumulate to toxic levels in plant tissues (Munns and Tester 2008).

The negative effects of salinisation on crop growth and the increasing land surface area suffering from it have an effect on food security and sustainability. Food security relates to all people having at all times, "physical, social and economic access to sufficient, safe and nutritious food to meet their dietary needs and food preferences for an active and healthy life" (FAO 2009). Food sustainability includes economic, social and environmental issues, representing the three classical dimensions

TABLE 2.1

\section{Sustainable Development Goals}

$\begin{array}{ll}\text { Goal Number } & \text { Theme } \\ \text { SDG1 } & \text { No Poverty } \\ \text { SDG2 } & \text { Zero Hunger } \\ \text { SDG3 } & \text { Good Health and Well-being } \\ \text { SDG4 } & \text { Quality Education } \\ \text { SDG5 } & \text { Gender Equality } \\ \text { SDG6 } & \text { Clean Water and Sanitation } \\ \text { SDG7 } & \text { Affordable and Clean Energy } \\ \text { SDG8 } & \text { Decent Work and Economic Growth } \\ \text { SDG9 } & \text { Industry, Innovation and Infrastructure } \\ \text { SDG10 } & \text { Reduced Inequality } \\ \text { SDG11 } & \text { Sustainable Cities and Communities } \\ \text { SDG12 } & \text { Responsible Consumption and Production } \\ \text { SDG13 } & \text { Climate Action } \\ \text { SDG14 } & \text { Life Below Water } \\ \text { SDG15 } & \text { Life on Land } \\ \text { SDG16 } & \text { Peace and Justice Strong Institutions } \\ \text { SDG17 } & \text { Partnerships to Achieve the Goals } \\ & \end{array}$


of sustainable development. Current farming practices exploit considerable amounts of natural resources, i.e. major shares of all ice-free land (33\%), freshwater (70\%) and energy production (20\%) (Smil 2001; Aiking 2014). Due to the continuing pressure on resources and land, as well as population growth leading to increased demands, food prices are expected to rise by $70-90 \%$ by 2030 (KPMG International et al. 2012). As a result, new innovative solutions need to be studied to increase food production through higher yields on degraded lands and to minimise pressure on the environment.

One of these options is saline agriculture. It involves irrigation solutions, different soil and water management and different crop species and variety choices. Thanks to these actions, despite degradation, saline lands can be further used for agricultural purposes. The choice of the methods to be applied on a selected area will depend on multiple factors such as the geomorphological and environmental aspects of the site, the socio-economic environment, the capacity of services and operational and maintenance factors (FAO 2018). The implementation of saline agriculture does not come without a cost. The management techniques usually require an initial investment in the irrigation system, equipment and/or seeds. There is also the risk of off-site effects. For example, saline irrigation could result in the pollution of groundwater or cause salinization of adjacent good quality land. These can also be seen as costs. At the same time, it brings benefits of enhanced global cooperation, the inclusion of private partners and civic society, as well as inspirational value for countries around the world.

Food production lies at the centre of saline agriculture. Rockström \& Sukhdev (2016) argue that all SDGs are linked to sustainable and healthy diets. They highlight that economies and societies are embedded in the environment connecting all related SDGs. In particular, they relate food to eradicating poverty (SDG 1) and famine (SDG 2), implementing gender equality (SDG 5), providing decent jobs (SDG 8 ) and reducing inequality (SDG 10). This approach suggests that the SDGs should be examined not separately but as a system of direct and indirect interconnections. These interconnections can occur at various stages of food production.

This paper addresses the research question of which SGDs are directly and indirectly related to the revitalisation of saline soils through saline agriculture. Our hypothesis is that saline agriculture supports the SDGs of food security (SDG 2), the use of freshwater resources (SDG 6), adaptation to climate change (SDG 13) and sustainable livelihoods (SDG 8). If not managed properly, it has the potential to have adverse effects on the marine (SDG 14) and terrestrial (SDG 15) biodiversity.

\subsection{METHODS}

To answer the research question, we applied a two-step research process. First, we constructed a simplified Drivers-Pressures-State-Impacts-Response (DPSIR) scheme to investigate the relationships between causes and consequences of salinization, and their links to SDGs. Second, we conducted semi-structured interviews with experts to discuss constraints and opportunities for saline agriculture and examine which SDGs' areas appear most often. 


\subsubsection{DPSIR FRAMEWORK}

Building on previous studies on salinization, we designed a simplified DPSIR scheme (Cooper 2013; Patrício et al. 2016). It was used to present connections between natural and social sciences related to the topic, and show the flow between actions and possible solutions for policymakers.

The DPSIR framework is a tool used to structure and understand various environmental and socio-economic activities better. Drivers can be described as "the social, demographic and economic developments in societies and the corresponding changes in lifestyles, overall levels of consumption and production patterns" (van Teeffelen 2017). These are the activities that are undertaken to enhance human wellbeing and welfare, often defined as the sectors that satisfy human needs (e.g. agriculture, industry, transport). Further, the pressure is a means by which the driver causes a change in the state. Then, states are changes in the properties of the natural environment. Consequently, an impact is an effect on welfare caused by the change in the state. Finally, responses are actions taken in reply to the changes in states and impacts (van Teeffelen 2017, pp. 43-55). The DPSIR framework is well fitted to analyse anthropocentric trade-offs in environmental decision-making, e.g. through cost-benefit analysis or input-output models (Cooper 2013).

The DPSIR scheme presented here was created in the research process which can be divided into two stages:

- Creating a database: A database of 72 documents, including scientific literature, conference proceedings, official publications and reports, related to the potential of saline agriculture was created using the following keywords in a Google Scholar search: saline agriculture, saline agriculture potential, saline agriculture benefits, saline agriculture challenges. Additional literature was added based on the recommendations from five experts in the field. The documents in the database were reviewed in order to make sure they addressed saline agriculture.

- Quantitative content analysis: Then the database was automatically searched with several keywords per SDG in the Atlas.ti software to score the number of times these SDG terms were mentioned. Keywords, such as desalination, agricultur* or climate change, associated with the 17 SDGs, can be found in the Appendix. Further, we quantified the number of SDGs mentioned in our database by counting the keywords associated to the SDGs and expressing them relative to the total number or presence of SDG keywords. Then, we summarised this information by designing a simplified DPSIR graph. For example, for SDG 6, we selected "Desalination" as one of the keywords because it is described in the targets. Then we scanned 72 publications related to saline agriculture for quotations with this keyword using Atlas.ti software. Further, we counted the number of quotations in which "Desalination" appears. We summed quotations for all the keywords for SDG 6. After analysing all the SDGs in this way, we converted the sum for each SDG into a percentage of total quotations.

The findings were compared with findings from the semi-structured interviews. 


\subsubsection{Semi-Structured Interviews}

Interviews with experts were conducted to understand various underlying conditions for saline agriculture. First, based on a literature review, we developed a questionnaire. Second, a pilot interview was conducted which allowed us to adjust questions and restructure the questionnaire. All experts were asked a similar set of questions, which was modified in certain cases to better fit their field of expertise. Third, experts for interviews were selected based on their publications and work in the field, as well as through the snowball sampling method (Christopoulos 2009). Another factor for respondents' selection was the geographical area of their expertise. Maximum variation sampling was used to provide a full picture of global potential. Eight of the experts consulted worked for large research centres, two for universities, two for consulting and training companies, and two for governmental institutions. Their areas of expertise included ecology and agriculture (three), land restoration (four), economics (three), policy (three), climate modelling (three), and soil research (two). Most scientists researched more than one field. Their expertise is concentrated in Australia, Bangladesh, Central Asia countries (e.g. Uzbekistan), Kenya, Middle East countries (e.g. Kuwait, United Arab Emirates, Qatar, Oman), Netherlands, Niger, Morocco, Pakistan, Russia, Sweden, Spain and the United Kingdom. Interviewees were coded from E1 to E11. Each interview was transcribed and summarised.

We conducted quantitative and qualitative content analysis. The summaries were coded automatically using selected keywords matching SDGs (see Appendix) to count their presence (direct quotations) and coded manually for expressions matching SDGs (indirect quotations). We defined a direct quotation as one including keywords assigned to an SDG. An indirect quotation was understood to be an expression which relates to an SDG but did not use selected keywords. This two-fold approach allowed for more precise analysis of the interviews. Further, we examined the summaries and selected four overarching SDG topics emerging from the experts' interviews.

\subsection{RESULTS}

This section presents the results of the DPSIR analysis and interviews with the experts. To facilitate comparison between the two approaches, we express the results in a comparative manner.

\subsubsection{From Drivers to Responses: SDGs in the Saline Agriculture}

Figure 2.1 shows the main causes and consequences of the salinization process. Due to the complexity of salinization and location-specific issues, only main phenomena were included in the graph which allowed us to track connections to SDGs. The DPSIR categories presented in Figure 2.1 are derived from the documents in our database.

Each category of the DPSIR framework relates to several SDGs which we outline in Table 2.2. For example, the drivers of salinization are mostly related to SDG 13 ("Climate action") and SDG 2 ("Zero hunger") and their targets.

Further, we investigated which SDGs were the most related to saline agriculture following the procedure described in Section 2.2. We scored the number of times each keyword related to SDG was mentioned in our database (Figure 2.2). 


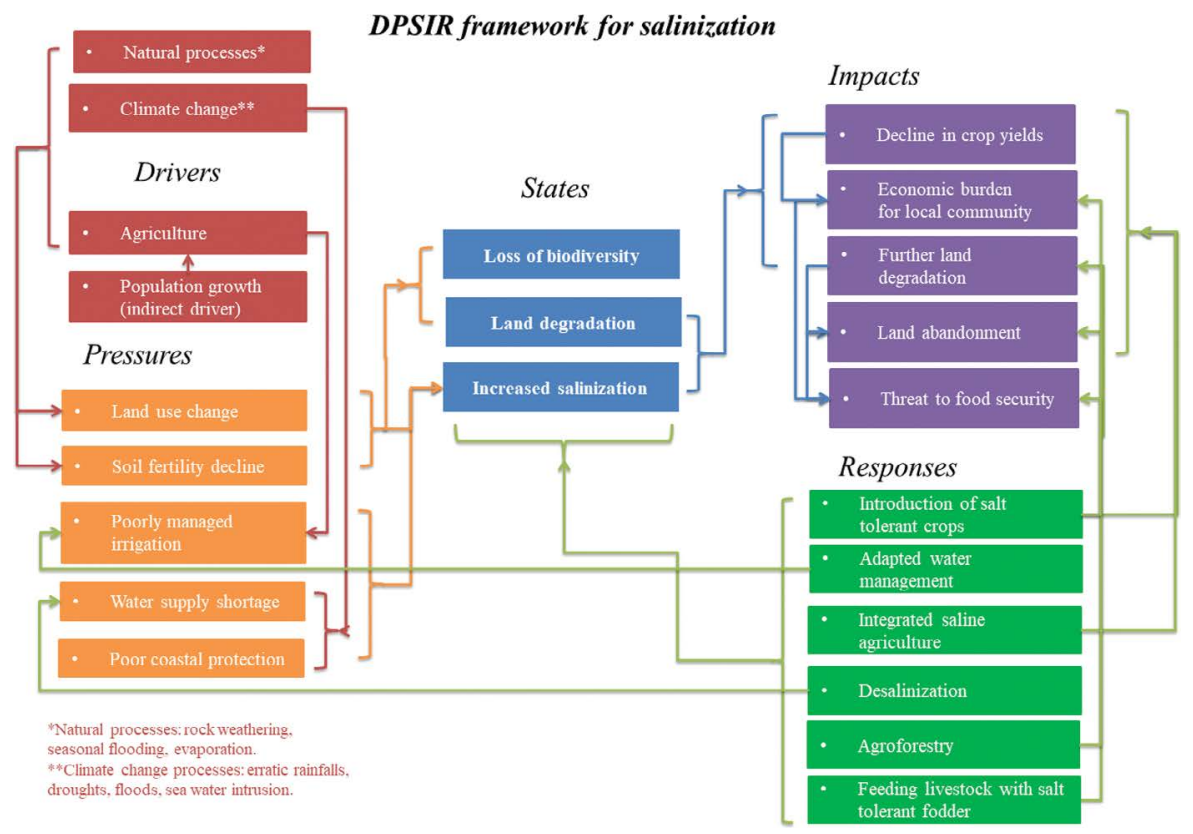

FIGURE 2.1 DPSIR research framework for salinization on a global, regional and local level. The two categories in the upper left corner of the figure, natural processes and climate change, are formally not part of the DPSIR's driver category but strongly affect direct and indirect drivers related to the process. The arrows represent casual relations between elements.

TABLE 2.2

\section{DPSIR-Related SDGs and SDG Targets}

\section{DPSIR}

Category

Drivers

Pressures

States

Impacts

Responses

\section{SDG Goal}

SDG 13 ("Climate action")

SDG 2 ("Zero hunger")

SDG 15 ("Life on land")

SDG 6 ("Clear water and sanitation")

SDG 14 ("Life below water")

SDG 15 ("Life on land")

SDG 6 ("Clear water and sanitation")

SDG 8 ("Decent work and economic growth")

SDG 2 ("Zero hunger")

SDG 15 ("Life on land")

SDG 9 ("Industry, innovation and infrastructure")

SDG 2 ("Zero hunger")

SDG 6 ("Clear water and sanitation")

\section{SDG Target}

13.1., 13.2.

$2.3,2.6$

$15.3,15.5,15.9$

$6.1,6.3,6.4,6.6 ., 6.7$

14.2

$15.3,15.5$

$6.3,6.4,6.5,6.6,6.7$

$8.2,8.3,8.5$

$2.1,2.3,2.4,2.5,2.6,2.7$

$15.3,15.5$

$9.1,9.4,9.5,9.7$

$2.1,2.3,2.4,2.5,2.6,2.7$

$6.3,6.4,6.5,6.6,6.7$ 


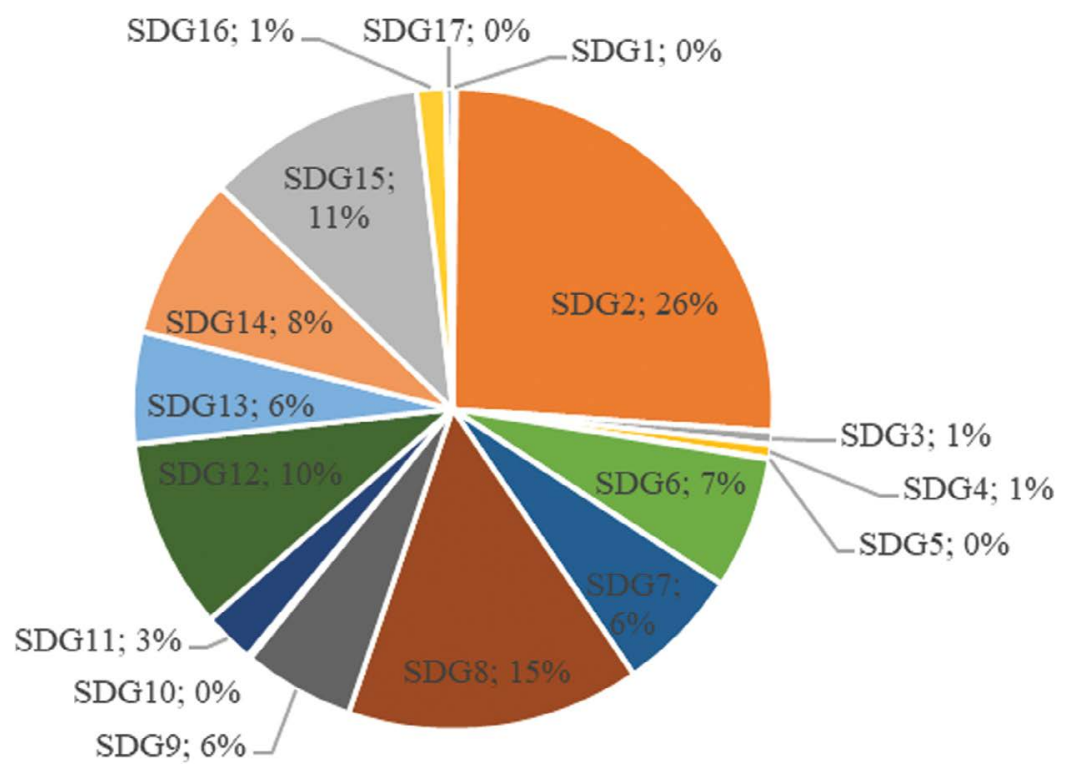

FIGURE 2.2 SDGs appearing in the articles by percentage of total quotations coded.

SDG 2 ("Zero hunger") was the most common (26\%), followed by SDG 8 ("Decent work and economic growth") with $15 \%$ and SDG 15 ("Life on land", 11\%). The least mentioned goals were SDG 1 ("No poverty"), SDG 5 (“Gender equality"), SDG10 ("Reduced inequality"), SDG 17 ("Partnerships"), scoring less than $1 \%$.

\subsubsection{SDGs ACCORDING TO EXPERTS}

We analysed the number of SDGs which appeared in the interviews (Figure 2.3). All but one SDG were mentioned directly or indirectly. SDG 2 "Zero hunger" accounted for $25 \%$ of total quotations. The second most mentioned was SDG 8 "Decent work and economic growth" related to sustainable livelihood (15\%). The third most common was SDG 6 "Clean water and sanitation" (13\%) (Figure 2.3).

We also examined which SDGs were mentioned directly and indirectly in the interviews (Figure 2.4). For the direct references, SDG 2 and SDG 8 appeared most commonly, followed by SDG 14. For the indirect references, SDG 6 and SDG 8 were referred to most often, followed by SDG 2 and SDG 9.

The interviews revealed a number of overarching themes from the perspective of reaching SDGs. First, there were certain conditions for the introduction of salt-tolerant crops which could be related to SDG 2 on food production. The second emerging theme was in impacts on economic development and possible scalability linked to SDG 8 economic development and SDG 12 on sustainable production and consumption. Third, interviewees mentioned some possible trade-offs of the revitalisation of saline degraded lands in the context of SDG 4 on education and SDG 15 on life on land. Fourth, they pointed to the impact of climate change on saline agriculture practices in the context of SDG 13 on climate. 


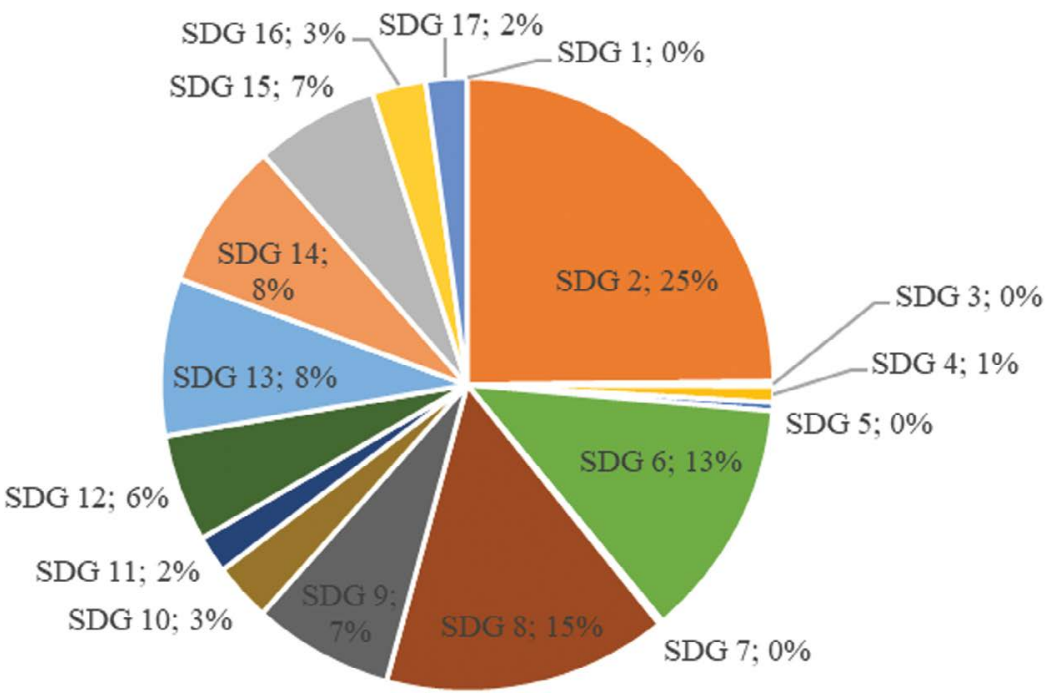

FIGURE 2.3 SDGs appearing in the interviews by percentage of total quotations coded.

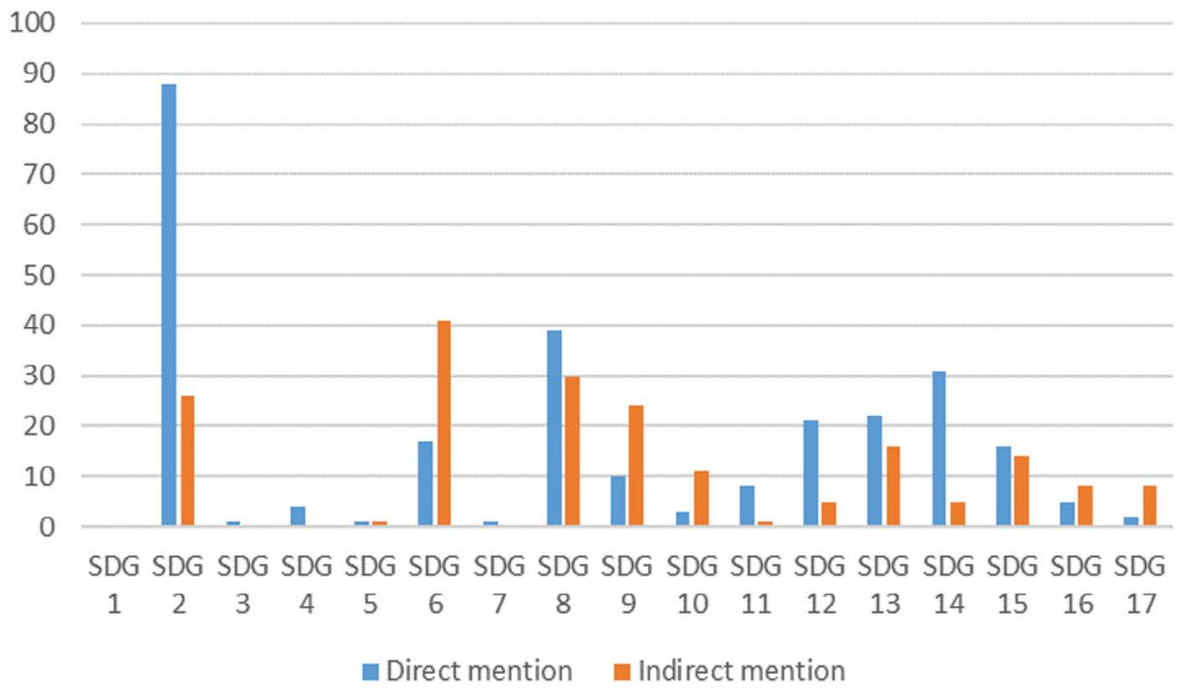

FIGURE 2.4 SDGs mentioned directly and indirectly in interviews.

\subsubsection{SDG 2: Conditions for the Introduction of Salt-Tolerant Crops}

This section outlines several conditions for growing salt-tolerant crops, including biophysical inputs, economic incentives, past habits, water management and a tailored approach for each case.

Experts named multiple conditions for the optimal use of saline soils and introduction of salt-tolerant crops. These conditions were summarised by two researchers: "[...] the future agricultural models should have the following characteristics: 1) 
require low use of chemical inputs, 2) ensure maximal water and nutrient recycling, 3) be cheap, cost-effective, 4) be easy to operate, 5) be nutrient-dense. Nutrientsensitive agriculture (nutritionally rich foods, dietary diversity, and food fortification) is really important as integrating different components gives a more thorough spectrum of elements, nutrients and vitamins" $\left(\mathrm{E} 5^{1}\right)$. One respondent suggested the importance of the measurement of salinity level, the water system management and presence of markets for the products (E10).

An important factor is taking into consideration the perspective of farming communities, including the opportunities for income diversification by use of integrated systems including crop cultivation and aquaculture (E5). E1 and E3 highlighted the importance of their access to resources, like fertilizers, seeds and additives, and a need for financial assistance, in the form of subsidies. The alternative solution mentioned by E3 and E2 is conservation or ecological agriculture. It is often an option for larger farms which can withstand yield fluctuations.

Current habits and practices, as well as historical conditions, constitute an important factor because farmers are unlikely to switch to a new type of crop (E1) and may traditionally prefer livestock farming, e.g. on saline pastures in Russia (E9).

Another key factor is proper water management, including leaching, drainage and monitoring (E9, E3, E2), which allows farmers to lower or keep the salinity level stable. Poor management may lead to increased salinization or high economic and environmental costs, e.g. when water is flushed through the fields without limits in Uzbekistan (E9). On the other hand, improving water harvesting practices, e.g. by establishing rainwater collecting points and underground storages, may help to maintain stable water supplies in regions with a changeable climate like Bangladesh (E1).

Proper research, including soil and water sampling, assessing the impact on the environment, seems to be the key to success. No one technique would fit all the areas: "The first step is always to identify the causes of salinization in the area supplemented with scientific diagnostics of the problems. Once these problems (salinity levels, sodicity level, hardpan, water table etc.) are diagnosed and based on what problems are existing at the site of interest, a combination of best management practices (integrated soil reclamation-irrigation \& drainage; physical \& chemical methods, biological-salt tolerant crops) is to be used which are site-specific. For example, if a hardpan is existing it must be broken down (subsoiling, chiselling etc.), high water table (drainage system to be installed), soil sodicity can be corrected using chemical amendment like gypsum etc. Salinity can be managed by using salt-tolerant crops and subsequent leaching fraction to maintain the root zone salinity below the crop threshold. Then, the crops are chosen and there is a large variety as it comes to salt tolerance level" (E10).

\subsubsection{SDG 8 and SDG 12: Impact on Economic Development and Scalability}

This section presents economic impacts of salinization including portfolio diversification, market development and the feasibility of upscaling.

Although economic aspects are widely discussed, little research has been done to fully estimate the economic aspects of saline agriculture for farmers with an assessment of scalability beyond a few hectares. For many farmers, portfolio diversification 
is fundamental as it makes them more resistant to sudden changes or less productive years. It helps not only the individuals but is also important for national food security and independence in this regard (E4, E5, E1). Saline agriculture has the potential to increase various farmers' income from diverse backgrounds, although in different ways. For farmers from developing countries, like Bangladesh, it is a way to avoid poverty and provide better living conditions. In a developed country, e.g. Australia, it is a source of competitive advantage (E3, E2).

Economic potential depends on the target country and the focus, like nutrition and food security, building market potential or commercialisation. The market for saline products is a factor often mentioned by experts. It is clear that to develop supply, the demand must exist. It would largely differ among countries. For example, developing countries struggling with food security are more likely to accept salt-tolerant varieties of conventional crops. At the opposite extreme, in developed countries, there is a high-end market for halophytes as delicacies (e.g. Salicornia has a very good selling price in the United Kingdom reaching $12 \mathrm{GBP} / \mathrm{kg}$ ). Building the market relates also to creating a supply chain for necessary materials, such as seeds or fertilizers. The markets currently exist in the Netherlands, the United Kingdom, United States of America and Belgium (E5). Another perspective is the pharmaceutical properties of these plants (E5). However, in some countries, there is no present economic imperative to cultivate saline degraded lands. This is especially valid for countries with a large amount of only slightly salt-affected surface area and rich organic soils, like Russia. It also depends on the key sectors in the country Gross Domestic Product (GDP), which for Uzbekistan is agriculture, thus being a point of focus. For others, like Iran, the political factors, e.g. relative isolation, may be a barrier to the flow of know-how and access to markets.

Finally, the most important factor for scaling up is the salinity level. Each salinity level has its economics which should not be compared with conventional agriculture. "The scaling up must be done where similar soil, water and environmental conditions may be existing, similar to where technology is going to be transferred. There must be a reason for scaling up based on market demand. If such information is not available then pilot-scale testing must be done before scaling up" (E10). Creating trust and establishing a business model is a way to scale up through establishing model farms and assigning the leading farmers who can later train their community (E1).

\subsubsection{SDG 4 and SDG 15: Possible Trade-Offs}

This section presents possible problems involved in application of saline agriculture such as improper water and soil management or threat for biodiversity.

Despite many benefits of saline agriculture, there are certain downsides of increasing human activities on saline degraded lands. The first one is the lack of knowledge because saline agriculture projects are generally multidisciplinary and require cooperation with an irrigation engineer, soil, horticultural and halophyte experts. The farmers become inspired by their neighbours, but do not seek expert advice and instead try to implement schemes themselves, which can lead to failure (E5). Salinization is often treated as a complex process with various phases. The management techniques may worsen the situation for a certain time, e.g. through dissolving 
the salt in the soil by leaching and pushing it to the upper layer. Eventually, the salinity level decreases, but the process may take many years (E9). Following this perspective, experts highlight the pressure on water systems and potential pollution from fertilizers, insecticides and pesticides (E10), but also returning extreme brine to the sea after desalination.

Increased agricultural production may affect biodiversity, especially if the lands are considered degraded, but are just semi-arid (E3). However, degradation also includes the low provision of ecosystem services, so agricultural restoration can be beneficial for ecosystem services linked to agro-biodiversity (E11).

\subsubsection{SDG 13: Impact of Climate Change}

This section presents effects of climate change on the process of salinization according to experts.

The impact of climate change on the process of salinization depends on the type of salinity and the level at which the salinity occurs. In some cases, if the soils are saline for geomorphic reasons and groundwater is very deep (more than 5-10 m), desertification may have no effect (E9). Climate change has a geographic pattern. For the Aral and Caspian Sea region, the main problem is sea-level change, which can be caused not only by climate but also by geology or through human-induced processes.

In some places, like the Netherlands, where the salinity issue is not visible now, climate change may lead to shifting climatic conditions in the future and a requirement to apply adaptive measures. Again, proper management is mentioned as one of the ways to avoid the negative consequences of climate change (E10).

Finally, the assessment of the climate change effect will depend greatly on the time frame. It may be minor within the next 20 years but have major implications in 50 years (E11). The experts perceive saline agriculture as a backup option for national food security and autonomy in case of unexpected or long-term climatic changes (E5).

\subsection{DISCUSSION}

Our findings show that almost all SDGs are related to the revitalisation of saline soils through saline agriculture. In particular, saline agriculture is highly related to SDG 2 and SDG 8 according to both methods used in this paper. In this way, it addresses food and water security through agricultural activities and water management (see Table 2.3).

There is surprising agreement between the two methods in the top- and lowestranked SDGs. The numbers differ (albeit slightly) for the SDGs moderately related to saline agriculture.

SDGs related to inequality, gender equality and partnerships for the goals are among the least scored in both the methods. However, saline agriculture creates an opportunity to address those goals, which should be more highlighted in future projects. Similarly, even though many current projects are focused on educating farmers, this is not reflected in the DPSIR analysis and the interviews. The reason for this may be a disparity between science and practice. In particular, the researchers often focus 
TABLE 2.3

Comparison of Number of Quotations between Our Two Methods

\begin{tabular}{llcc} 
SDG & & DPSIR (\%) & Interviews (\%) \\
SDG1 & "No poverty" & 0 & 0 \\
SDG2 & "Zero hunger" & 26 & 25 \\
SDG3 & "Good health and well-being" & 1 & 0 \\
SDG4 & "Quality education" & 1 & 1 \\
SDG5 & "Gender equality" & 0 & 0 \\
SDG6 & "Clean water and sanitation" & 7 & 13 \\
SDG7 & "Affordable and clean energy" & 6 & 0 \\
SDG8 & "Decent work and economic growth" & 15 & 15 \\
SDG9 & "Industry, innovation and infrastructure" & 6 & 7 \\
SDG10 & "Reduced inequalities" & 0 & 3 \\
SDG11 & "Sustainable cities and communities" & 3 & 2 \\
SDG12 & "Responsible consumption and production" & 10 & 6 \\
SDG13 & "Climate action" & 6 & 8 \\
SDG14 & "Life below water" & 8 & 8 \\
SDG15 & "Life on land" & 11 & 7 \\
SDG16 & "Peace, justice and strong institutions" & 1 & 3 \\
SDG17 & "Partnerships for the goals" & 0 & 2 \\
\hline
\end{tabular}

on innovations in plant physiology rather than on how to make the results of their studies accessible to a wider audience.

Based on the results of this study, future research could explore how saline agriculture fits in the DPSIR framework related to food production as a valuable addition to conventional agriculture as it comes to addressing food security. Our study of saline agriculture confirms Rockström \& Sukhdev's (2016) argument that all SDGs are related to food. These food security and sustainability issues are present in developing countries (see, e.g. Ladeiro 2012; Chapter 21 of this book). The nexus nature of saline agriculture can be a sustainable land management practice in countries confronting salt-induced land degradation (Qadir et al. 2014).

The DPSIR analysis in this paper partially overlaps with the results obtained by Ruto et al. (2018). However, the causes, impacts and state of the salinization described in their report focus more on the physical and economic aspects of the process.

Our results partly align with SDGs reported in the study of Chapter 21 in this book. Its findings include SDG 2 and SDG 13 which score high in this research, but also SDG 1, SDG 3, SDG 5 and SDG 17 which are among the least addressed SDGs in our study. The reason for this difference may be that the study of Chapter 21 focused on a community-oriented project.

What is surprising in our study is the relatively weak link to SDG 5 "gender equality", which is often mentioned by other studies and programs, e.g. network for the Arab Women Leaders in Agriculture (AWLA) fellowship program (ICBA, 2020). Also, SDG 1 "No poverty" was not covered in the interviews, which may come 
from the fact that farmers involved in the community live above the poverty line. Finally, the partnerships (SDG 17) were mentioned less often than expected, while it seems that the community of practice and science is emerging. A reason for this result may be a choice of the keywords for this SDG. Future studies could explore it more in the context of funding possibilities and development aid.

Additionally, the link to climate is also weaker than expected. Saline agriculture can be more pronounced as a countermeasure for economic and climate migration. For example, in Bangladesh, increasingly severe floods will push salt water more inward across land (Chen \& Mueller 2018). This will affect the livelihoods of the coastal and delta-area people (SDG 11) as locally there will be less productive agricultural activity (SDG 8). As a result, people are likely to migrate away from the Delta with many negative social and political consequences. Subsequently, SDG 8 ensuring decent and economic growth in coastal areas is a major goal supporting food production under saline soil and water conditions.

Finally, implementation of saline agriculture may involve some trade-offs, as Bailis \& Yu (2012) suggest. These trade-offs could happen in places of ecological or cultural significance. Potential synergies and barriers among SDGs in relation to saline agriculture should be further investigated.

\subsection{CONCLUSION}

Our study analyses in a systematic way SDGs connected to salinization by employing the DPSIR framework and the analysis of semi-structured expert interviews. We conclude that both methods consequently point to SDG 2 ("Zero hunger") and SDG 8 ("Decent work and economic growth") as being strongly related to saline agriculture. These results are partially in line with our hypothesis pointing towards SDG 2, SDG 6, SDG 8, SDG 13, SDG 14 and SDG 15.

Based on our findings, we formulate the following recommendations:

- The revitalisation of saline soils through saline agriculture can foster achieving SDG 2 and SDG 8, especially in salt-affected regions struggling with food and water security.

- The management of saline soils can create workplaces for local farmers, increase income through higher yields than with conventional crops, and prevent or reduce economic and climate migrations (SDG 8).

- Revitalisation projects should focus more on the education (SDG 4) of underprivileged target groups (SDG 10) and woman (SDG 5) to allow for synergy effects. It could be achieved by partnerships (SDG17) among various stakeholders.

Our analysis shows that saline agriculture is a nexus area linking food production, water management and sustainable economic development. Investments in this method of revitalisation can address multiple SDGs at the same time. Policymakers and other actors should take these findings into account as saline agriculture is an effective way to meet SDGs and combat the challenges of deteriorating food security and increasing climate change. 


\section{APPENDIX - CODE BOOK}

\begin{tabular}{|c|c|c|}
\hline Sustainable Development Goals SDG & $\begin{array}{l}\text { Directly Mentioned } \\
\text { (Interviews) }\end{array}$ & Directly Mentioned (DPSIR) \\
\hline GOAL 1: No Poverty & Poverty & Poverty \\
\hline \multirow[t]{4}{*}{ GOAL 2: Zero Hunger } & Food & Food \\
\hline & Agricultur* & Agricultur* \\
\hline & Genetic & Genetic \\
\hline & Seeds & Seeds \\
\hline \multirow[t]{2}{*}{ GOAL 3: Good Health and Well-being } & Health & Health \\
\hline & Well-being & Well-being \\
\hline \multirow[t]{3}{*}{ GOAL 4: Quality Education } & Education & Education \\
\hline & Training & Training \\
\hline & Teach & Teach \\
\hline \multirow[t]{2}{*}{ GOAL 5: Gender Equality } & Gender & Gender \\
\hline & Woman & Woman \\
\hline \multirow[t]{5}{*}{ GOAL 6: Clean Water and Sanitation } & Clean & Clean \\
\hline & Desalination & Desalination \\
\hline & Wastewater & Wastewater \\
\hline & Reuse & Reuse \\
\hline & Groundwater & Groundwater \\
\hline \multirow[t]{2}{*}{ GOAL 7: Affordable and Clean Energy } & Energy & Energy \\
\hline & Biomass & Biomass \\
\hline \multirow{4}{*}{$\begin{array}{l}\text { GOAL 8: Decent Work and Economic } \\
\text { Growth }\end{array}$} & Employment & Employment \\
\hline & Economy & Economy \\
\hline & Economic & Economic \\
\hline & Growth & Growth \\
\hline \multirow{3}{*}{$\begin{array}{l}\text { GOAL 9: Industry, Innovation and } \\
\text { Infrastructure }\end{array}$} & Industry & Industry \\
\hline & Innovat* & Innovat* \\
\hline & Technolog* & Technolog* \\
\hline \multirow[t]{2}{*}{ GOAL 10: Reduced Inequality } & Equality & Equality \\
\hline & Migration & Migration \\
\hline \multirow{3}{*}{$\begin{array}{l}\text { GOAL 11: Sustainable Cities and } \\
\text { Communities }\end{array}$} & Cities & Cities \\
\hline & Urban & Urban \\
\hline & Community & Community \\
\hline \multirow{3}{*}{$\begin{array}{l}\text { GOAL 12: Responsible Consumption and } \\
\text { Production }\end{array}$} & Production & Production \\
\hline & Consumption Consumer & Consumption \\
\hline & & Consumer \\
\hline GOAL 13: Climate Action & Climate change & Climate change \\
\hline \multirow[t]{5}{*}{ GOAL 14: Life Below Water } & Water (mannually & (Water excluded) \\
\hline & cross-checked) & Marine \\
\hline & Marine & Coastal \\
\hline & Coastal & Fish \\
\hline & Fish & \\
\hline \multirow[t]{5}{*}{ GOAL 15: Life on Land } & Land degradation & Land degradation \\
\hline & Soil degradation & Soil degradation \\
\hline & Biodiversity & Biodiversity \\
\hline & Desert & Desert \\
\hline & Ecosystem & Ecosystem \\
\hline
\end{tabular}




\begin{tabular}{lll} 
Sustainable Development Goals SDG & $\begin{array}{l}\text { Directly Mentioned } \\
\text { (Interviews) }\end{array}$ & Directly Mentioned (DPSIR) \\
\hline GOAL 16: Peace and Justice Strong & Institution & Institution \\
Institutions & Law & Law \\
& Regulation & Regulation \\
GOAL 17: Partnerships to achieve the & Partnership & Partnership \\
Goal & Cooperation & Cooperation \\
\hline
\end{tabular}

\section{ENDNOTE}

1. Interviewees were coded from E1 to E11.

\section{ACKNOWLEDGMENTS}

We would like to express our gratitude to all the experts participating in the interviews for their time, patience and sharing their knowledge.

\section{REFERENCES}

Aiking, H. (2014). Protein production: Planet, profit, plus people?-. The American Journal of Clinical Nutrition, 100(suppl_1), 483S-489S.

Bailis, R., \& Yu, E. (2012). Environmental and social implications of integrated seawater agriculture systems producing Salicornia bigelovii for biofuel. Biofuels, 3(5), $555-574$.

Chen, J., \& Mueller, V. (2018). Coastal climate change, soil salinity and human migration in Bangladesh. Nature Climate Change, 8(11), 981-985.

Christopoulos, D. (2009). Peer Esteem Snowballing: A methodology for expert surveys. Eurostat Conference for New Techniques and Technologies for Statistics, 171-179.

Cooper, P. (2013). Socio-ecological accounting: DPSWR, a modified DPSIR framework, and its application to marine ecosystems. Ecological Economics, 94, 106-115. https://doi. org/10.1016/j.ecolecon.2013.07.010

Dagar, J. C., Sharma, P. C., Sharma, D. K., \& Singh, A. K. (2016). Innovative saline agriculture. Springer.

Dagar, J. C., Yadav, R. K., \& Sharma, P. C. (2019). Research developments in saline agriculture. Springer.

Datta, K. K., \& Jong, C. de. (2002). Adverse effect of waterlogging and soil salinity on crop and land productivity in northwest region of Haryana, India. Agricultural Water Management, 57(3), 223-238. https://doi.org/10.1016/S0378-3774(02)00058-6

De Waegemaeker, J. (2019). SalFar framework on salinization processes. A report by ILVO for the Interreg VB North Sea Region project Saline Farming (SalFar). http://scholar. googleusercontent.com/scholar?q=cache:sh0r_1_FkcsJ:scholar.google.com/+De+Waegem aeker,+J.+(2019).+SalFar+framework+on+salinization+processes.+\&hl=pl\&as_sdt=0,5

FAO. (2009). World summit on food security. Declaration of the World Summit on food security. FAO. http://ftp.fao.org/docrep/ fao/Meeting/018/k6050e.pdf

FAO. (2011). The state of the world's land and water resources for food and agriculture: managing systems at risk. Food and Agriculture Organization of the United Nations.

FAO. (2018). More information on Salt-affected soils | FAO SOILS PORTAL | Food and Agriculture Organization of the United Nations. http://www.fao.org/soilsportal/soil-management/management-of-some-problem-soils/salt-affected-soils/ more-information-on-salt-affected-soils/en/ 
Ghassemi, F., Jakeman, A. J., \& Nix, H. A. (1995). Salinisation of land and water resources: Human causes, extent, management and case studies. CAB International.

Hülsmann, S., \& Ardakanian, R. (Eds.). (2018). Managing water, soil and waste resources to achieve sustainable development goals. Springer International Publishing. https://doi. org/10.1007/978-3-319-75163-4

ICBA. (2020, May 4). ICBA launches virtual alumnae network to support Arab women researchers | Awla. https://www.awlafellowships.org/news/icba-launches-virtualalumnae-network-support-arab-women-researchers

Joe-Wong, C., Schlesinger, D., Chow, A., \& Myneni, S. C. B. (2019). Sea level rise produces abundant organobromines in salt-affected coastal wetlands. Geochemical Perspectives Letters, 10, 31-35.

KPMG International, De Boer, Y., \& van Bergen, B. (2012). Expect the unexpected: Building business value in a changing world. KPMG International.

Ladeiro, B. (2012). Saline agriculture in the 21st century: Using salt contaminated resources to cope food requirements. Journal of Botany, 2012, 1-7. https://doi. org/10.1155/2012/310705

Liu, J., Hull, V., Godfray, H. C. J., Tilman, D., Gleick, P., Hoff, H., Pahl-Wostl, C., Xu, Z., Chung, M. G., Sun, J., \& Li, S. (2018). Nexus approaches to global sustainable development. Nature Sustainability, 1(9), 466-476. https://doi.org/10.1038/ s41893-018-0135-8

Munns, R., \& Tester, M. (2008). Mechanisms of salinity tolerance. Annu. Rev. Plant Biol., 59, 651-681.

Patrício, J., Elliott, M., Mazik, K., Papadopoulou, K.-N., \& Smith, C. J. (2016). DPSIR-two decades of trying to develop a unifying framework for marine environmental management? Frontiers in Marine Science, 3. https://doi.org/10.3389/fmars.2016.00177

Qadir, M., Quillérou, E., Nangia, V., Murtaza, G., Singh, M., Thomas, R. J., Drechsel, P., $\&$ Noble, A. d. (2014). Economics of salt-induced land degradation and restoration. Natural Resources Forum, 38(4), 282-295. https://doi.org/10.1111/1477-8947.12054

Rockström, J., \& Sukhdev, P. (2016, June 14). How food connects all the SDGs-Stockholm Resilience Centre [Text]. https://www.stockholmresilience.org/research/researchnews/2016-06-14-how-food-connects-all-the-sdgs.html

Ruto, E., Gould, I., Bosworth, G., \& Wright, I. (2018). The state, causes and impact of soil salinization: A global overview (pp. 1-13). SalFar Work Package 3 Baseline January 2018 Report.

Smil, V. (2001). Feeding the world: A challenge for the twenty-first century. MIT press.

Stoorvogel, J. J., Bakkenes, M., \& Brink, B. J. E. (2017). To what extent did we change our soils? A global comparison of natural and current conditions. Land degradation \& development, 28(7), 1982-1991.

van Noordwijk, M., Duguma, L. A., Dewi, S., Leimona, B., Catacutan, D. C., Lusiana, B., Öborn, I., Hairiah, K., \& Minang, P. A. (2018). SDG synergy between agriculture and forestry in the food, energy, water and income nexus: Reinventing agroforestry? Current Opinion in Environmental Sustainability, 34, 33-42. https://doi.org/10.1016/j. cosust.2018.09.003

van Teeffelen, A. (2017, September 4). Causes and consequences of environmental change. ERM, Amsterdam.

Vos, Arjen de, Andres Parra González, and Bas Bruning. 2021. "Case Study: Putting Saline Agriculture into Practice - A Case Study from Bangladesh.” In Future of Sustainable Agriculture in Saline Environments. Routledge, Taylor \& Francis Group, London. 